five. The curves are inverted, so that high points represent early dates and low points late dates.

Other examples might be given. This line of inquiry has been followed to some extent by $M$. Flammarion in France, and it seems desirable that attention should be given to it in this country by those interested in phenology.

The contrast above referred to between the relations of sun-spots and temperature in western Europe and those

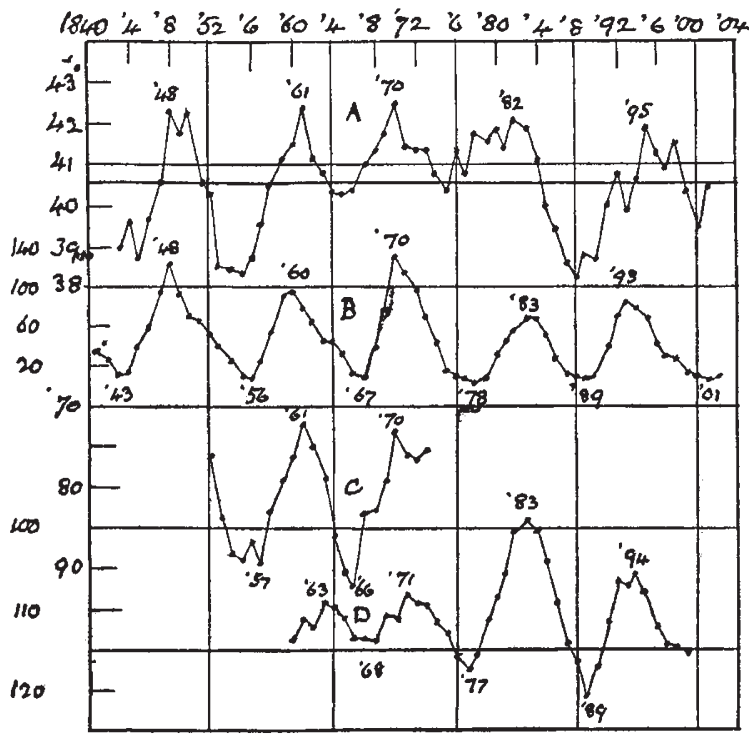

in the tropics also calls for elucidation. Probably no meteorologist would now regard it (or other such contrasts) as fatal to the idea of sun-spot influence.

Alex. B. MacDowall.

\section{Retarded Motion of the Great Red Spot on Jupiter.}

Perhaps the most notable fact brought to light by observations of Jupiter during the present season is that the velocity of the great red spot has been again retarded. The rotation period of this well-known object has been as follows in recent years:-

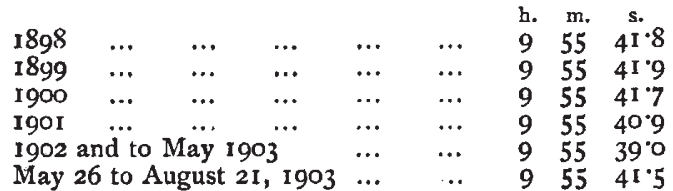

At the end of May last the longitude of the spot was about $30^{\circ}$, whereas at the present time it is $32^{\circ}$, indicating an easterly drift of $2^{\circ}$, whereas during the preceding twelve months the marking had shown a westerly drift of about $i^{\circ}$ per month. The spot now follows the zero meridian (system ii. of Mr. Crommelin's ephemeris, Monthly Notices R.A.S., 1xiii, p. IIo, December, 1902) by about 53 minutes. A remarkable disturbance has recently occurred in the southern equatorial belt of Jupiter. In about longitude $140^{\circ}$ to $175^{\circ}$ (system i.) several nearly black spots have appeared, and the belt in this region is much torn and full of irregularities, changing from night to night, and evidently subject to extensive commotions.

W. F. Denning.

\section{The Spots on Saturn.}

DURING the past two months about 75 transit times of these objects have been taken here. Several of the more conspicuous markings are moving slower than expected, and their positions appear to be well represented by $d$ rotation period of about 1oh. $39 \frac{1}{2} \mathrm{~m}$.

Bishopston, Bristol, August 25.

$$
\text { W. F. Denning. }
$$

THE SOUTHPORT MEETING OF THE BRITISH ASSOCIATION.

SINCE the prospective programmes of the various sections of the British Association were obtained for last week's Nature, the following additional particulars referring to the subsection of Section A, devoted to astronomy and meteorology, and the International Meteorological Committee have been received from Dr. W. N. Shaw, chairman of the subsection.

It is intended that the subsection shall meet on Friday, September II, and on the following Monday and Wednesday. The proceedings may be expected to be especially interesting on account of the presence of a number of distinguished meteorologists from foreign countries who will be in Southport in connection with the meeting of the International Committee. It is hoped that arrangements can be made to enable the members of the committee to take part in the meetings of the subsection, although separate meetings of the committee must be held for the transaction of business.

The questions already proposed for discussion by the Committee include the initiation of international cooperation in connection with atmospheric electricity and solar physics, and its extension as regards terrestrial magnetism; the revision of the arrangements for the exchange of daily telegraphic reports, and the modification of some of the existing international conventions with regard to the observations made at stations of various orders and the method of recording them.

In the subsection on September II, after an address by the chairman on methods of meteorological investigation, the president of the Association, Sir N. Lockyer, will read a paper on the correlation of solar and terrestrial phenomena, which will be followed by a discussion, as a preliminary to a proposal for putting the organisation of work in connection with that subject upon an international basis. Dr. Buchan will contribute a communication illustrating the distribution of rainfall in Scotland according to the succession of years of the sun-spot cycle. At the same session it is hoped that some of the members of the International Meteorological Committee who have taken a prominent part in the prosecution of researches in connection with that committee may be able to contribute papers. In particular the work of the committee on cloud observations has recently been brought to a conclusion, and a summary of the final results achieved would be very acceptable.

For any further available time on that or the other days there is already a substantial programme. Various astronomical fapers have been referred to in the previous notice. The committees which have to present reports are those on kite observations, on the Ben Nevis Observatory, and on seismological observations, and any one of them, either of themselves or in connection with papers on special points associated with them, may give rise to valuable discussion. Prof. Hergesell, the chairman of the aëronautical committee, will be able to give the latest information as to the international investigation of the upper air, and Dr. Varley will exhibit the record obtained by him for Mr. P. Y. Alexander with an unmanned balloon that reached the extraordinary height of 70,000 feet on a journey from Bath in July. The kite equipment and method of investigation employed by Mr. Dines will be exhibited, if possible, in action.

Prof. Callendar will speak upon self-recording in. struments, and thus open the way for the discussion of a subject which is of pressing importance in cooperative meteorological work. 